\title{
Cidadania ou "estadania" na gestão pública brasileira?
}

\author{
Daniela Meirelles Andrade \\ Universidade Federal de Lavras \\ Carolina Lescura de Carvalho Castro \\ Universidade Federal Fluminense \\ José Roberto Pereira \\ Universidade Federal de Lavras
}

\begin{abstract}
O processo de democratização brasileira ocorreu de uma forma bem diferente da vivenciada por outros países, como Estados Unidos da América e França. Nesse sentido, o objetivo deste artigo teórico é apresentar os elementos centrais sobre democracia e cidadania e demonstrar como a formação histórica do Estado brasileiro impulsionou o fortalecimento de uma "estadania" nacional em detrimento da cidadania. Demonstrou-se que a formação do Estado brasileiro é um entrave para a consolidação da cultura cívica, pois não consegue desenvolver os direitos sociais, políticos e civis como apresentados por Marshall. Assim, o que se percebe é que o exercício da democracia não é uma tarefa fácil, porém, para uma nação evoluir em termos de participação efetiva dos cidadãos, os mesmos precisam participar do processo. No Brasil, nota-se prevalência de ações que conferem maior poder ao Estado, como responsável pela estruturação e desenvolvimento da vida social. Portanto, prevalece em nossa nação a "estadania", visto a ausência de uma cultura cívica, cabendo aos atores não estatais um papel de coadjuvantes no processo. Por outro lado, mudanças relacionadas à democratização mais efetiva do Estado e à democratização da própria democracia fazem-se necessárias.
\end{abstract}

Palavras-chave: “estadania”; democracia; formação do estado brasileiro.

\section{Citizenship or "stateship" in public management in Brazil?}

The democratization process in Brazil occurred in a manner quite different from that experienced by other countries like USA and France. In this sense, the objective of this theoretical essay is to present the core elements of democracy and citizenship, and demonstrate how the historic formation of the Brazilian state boosted the strength of a "stateship" at the expense of national citizenship. It was demonstrated that the formation of the Brazilian state is an obstacle to the consolidation of civic culture, because it can not develop social rights, political and civil as presented by Marshall. Thus, we can see

Artigo recebido em maio 2010 e aceito em jul. 2011. 
is that the exercise of democracy is not an easy task, but for a nation to evolve in terms of effective participation of citizens, they have to participate in the process. In Brazil, there is prevalence of actions that give more power to the State as responsible for structuring and development of social life. So prevalent in our nation "stateship", since the absence of a civic culture, while the non-state actors a facilitating role in the process. Moreover, changes related to democratization more effective state and the democratization of democracy itself are necessary.

Key words: "stateship"; democracy; the formation of the Brazilian state.

\section{Introdução}

O processo de democratização brasileira ocorreu de uma forma bem diferente da vivenciada por outros países, como Estados Unidos e França. A construção de uma cultura cívica, bem como da cidadania, deu-se de maneira distinta, marcada por forte tradição cultural centrada no Estado em relação à sociedade e ao mercado, o que permitiu a Carvalho (1996), ao analisar o longo percurso da "cidadania" no Brasil, cunhar o termo "estadania" como forma de expressar a negatividade histórica da cidadania.

O objetivo deste artigo teórico é apresentar os elementos centrais sobre democracia e cidadania e demonstrar como a formação histórica do Estado brasileiro impulsionou o fortalecimento de uma "estadania" nacional em detrimento da cidadania. Nesse sentido, levantamos uma questão norteadora deste artigo: a administração pública no Brasil atua a favor da construção da cidadania ou representa a administração do Estado centralizador?

Este artigo torna-se relevante na medida em que se discute o cenário da administração pública brasileira diante do processo de formação de nossa cidadania. Procura-se neste artigo diferenciar a nossa formação democrática e cívica, em relação a outros países. Os direitos sociais, no caso brasileiro, são reforçados em função da ausência dos direitos civis e mesmo políticos, pois, de acordo com Carvalho (2007), não havia nem autonomia para escolher os representantes. Todos esses aspectos são traços fortes do processo de colonização portuguesa no Brasil.

Este artigo foi estruturado em quatro partes, além desta introdução. Na primeira apresentamos alguns aspectos históricos e conceituais sobre a democracia e sua importância para a construção da cidadania. Na segunda parte, discorre-se sobre cidadania evidenciando seus principais conceitos. Na terceira parte é apresentada, de forma sucinta, a história de formação do Estado brasileiro. A quarta seção tem por objetivo demonstrar como a própria formação do Estado brasileiro constitui-se em um entrave para a consolidação de uma cultura cívica, pois no Brasil não se conseguem desenvolver, plenamente e de forma simultânea, os direitos sociais, políticos e civis como apresentados por Marshall. Por fim, retoma-se o objetivo do trabalho e são tecidas algumas reflexões finais. 


\section{Aspectos conceituais de democracia}

Tratando de aspectos históricos, o termo "democracia" foi mencionado pela primeira vez no século $\mathrm{V}$ a.C., pelo historiador grego Heródoto, quando quis se referir a "governo do povo" (Khan, 2001). Contudo, apesar de seu longínquo surgimento, nota-se que o debate sobre democracia é atual e constitui-se em um dos assuntos de maior relevância quando se discute política, participação social e gestão pública.

A coexistência de uma pluralidade de definições acerca do que vem a ser democracia torna o diálogo rico, na medida em que aglutina diferentes concepções, compreendendo diversas abordagens teóricas.

De acordo com Bobbio (1986:12), o regime democrático pode ser entendido como "um conjunto de regras (primárias ou fundamentais) de procedimentos para a formação de decisões coletivas, em que está prevista e facilitada a participação mais ampla possível dos interessados".

Na concepção de Dahl (2001), a democracia é compreendida como um conjunto de regras e princípios de uma constituição, que determinará como serão tomadas as decisões da sociedade. Nessa constituição, todos os membros devem ser tratados como se estivessem qualificados para tomar as diretrizes sobre as políticas a serem seguidas. Portanto, nessa concepção de Dahl (2001), os sujeitos devem ser considerados politicamente iguais.

Dando continuidade à linha de raciocínio de Dahl, cabe questionar: quais critérios devem ser a priori estabelecidos para que os cidadãos sejam considerados efetivamente iguais e, assim, possam participar das decisões políticas? Na tentativa de responder esta indagação, Dahl (2001) elenca cinco princípios fundamentais da democracia:

- participação efetiva: todos os sujeitos devem possuir oportunidades iguais e efetivas, para que possam se expressar livremente;

- igualdade de voto: ao realizar uma decisão política, é necessário que todos os membros tenham oportunidades iguais e efetivas de voto;

v entendimento esclarecido: cada sujeito deve ter oportunidades iguais e efetivas de aprender sobre as políticas alternativas importantes e suas prováveis consequências;

- controle do programa de planejamento: os indivíduos devem ter plena oportunidade para decidir como e quais questões devem ser colocadas no planejamento de sua cidade/região/ país;

- inclusão dos adultos: a maioria dos adultos residentes permanentes deve possuir o pleno direito de cidadão, ou seja, devem exercer a participação efetiva.

Dahl (2001) completa a reflexão sobre esses cinco princípios fundamentais da democracia enfatizando que, quando um desses critérios supracitados é violado, os sujeitos não são considerados politicamente iguais. 
Ainda de acordo com Dahl (2001), a democracia em sua essência evita a tirania, possibilita direitos essenciais aos cidadãos, proporciona a liberdade, a autodeterminação, a autonomia moral, o desenvolvimento humano, a proteção dos interesses pessoais essenciais, a igualdade política, a busca pela paz e a prosperidade. Contudo, Dahl ressalva que a democracia não é capaz de assegurar que os cidadãos sejam felizes, prósperos e saudáveis, sábios, pacíficos ou justos. Na concepção de Dahl, atingir esses fins está além da capacidade de qualquer governo, inclusive o democrático.

Putnam (2007), quando se refere à democracia, pontua três aspectos que influenciam a dinâmica do desempenho de instituições democráticas. A primeira corrente enfatiza o "projeto institucional". Esta corrente de pensamento versa essencialmente sobre a engenharia institucional, ou seja, busca investigar as formas mais adequadas para garantir um governo representativo eficaz. Assim, essa linha defende que, para se obter um governo representativo viável, é necessária uma reestruturação nos projetos institucionais, criando estruturas voltadas para o ideal democrático.

A segunda corrente de pensamento, no que se refere ao desempenho das instituições democráticas, tratada por Putnam (2007), enfatiza os "fatores socioeconômicos". Essa linha vai de encontro a um dos critérios condicionantes para o exercício da democracia, estabelecidos por Dahl. Assim, a ênfase nos fatores socioeconômicos preconiza a necessidade de fornecer condições básicas aos cidadãos, pois este seria um dos pilares centrais para a construção de um governo democrático, estável e eficaz.

Por fim, a terceira corrente destaca a importância dos "fatores socioculturais" no desempenho das instituições democráticas. Putnam (2007) explica que os governos podem variar de acordo com a disposição de seus cidadãos. Em outros termos, Putnam exalta que os costumes de uma sociedade, bem como suas práticas políticas, são determinantes para a construção de uma "cultura cívica". Esta cultura cívica é essencial para o fortalecimento de instituições democráticas estáveis e eficazes.

Outro autor que discute amplamente a questão da democracia é Alexis de Tocqueville. Para Tocqueville (1987), a sociedade democrática é aquela em que não existem distinções de ordens e de classes. De acordo com Tocqueville, o fato de os indivíduos serem socialmente iguais não corresponde a uma igualdade econômica, mas sim a uma inexistência de diferenças hereditárias de condições. Tocqueville ressalta que o governo adaptado a essa sociedade igualitária poderia ser denominado governo democrático.

No debate sobre democracia, duas formas são usualmente discutidas pelos teóricos: a democracia participativa e a democracia representativa. Tenório (2007) afirma que na democracia representativa observa-se participação política limitada por parte dos cidadãos e uma distância entre representantes e representados. Na democracia participativa ocorre um processo de conexão da sociedade com o poder público na dinâmica de formulação de políticas. De acordo com Dahl (2001), a democracia participativa proporciona aos cidadãos boas oportunidades de se envolverem no processo de governar a si mesmos, enquanto em um governo representativo em uma grande unidade isso não seria possível. Por outro lado, Dahl (2001) aponta alguns problemas na utilização da democracia participativa ou de assembleia. Esses 
problemas estão relacionados ao fato de que a oportunidade para participar diminui com a amplitude do tamanho do corpo de cidadãos. A possibilidade de o participante expressar-se por meio da oratória em uma reunião é pequena e os que participam tornam-se representantes dos outros, exceto no voto.

Tendo discutido alguns elementos centrais para a compreensão da democracia, cabe destacar um ponto principal: a democracia é fundamental para a compreensão da cidadania pois, de acordo com Touraine (1996), "não há democracia sem cidadania". Assim, na próxima seção serão discutidos aspectos relacionados à formação de uma nação cidadã, em que a participação efetiva do cidadão é praticamente um pré-requisito, podendo ocorrer por meio da política, da justiça social e dos direitos civis.

\section{Caminhos da cidadania}

A cidadania, segundo Carvalho (2001), pode ser compreendida como a integração das pessoas no governo via participação política, via garantia de direitos individuais, via justiça social. Segundo Carvalho, a cidadania permanece sendo a aspiração de quase todos os países, em especial aqueles que se enquadram na tradição ocidental.

De acordo com Carvalho (2007), tornou-se costume desdobrar a cidadania em "direitos civis, políticos e sociais". Assim, o cidadão pleno seria aquele que fosse titular dos três direitos, o cidadão incompleto aquele que possui apenas alguns direitos e o não cidadão aquele que não possui direitos.

Carvalho elucida que os "direitos civis" são os fundamentais à vida, à liberdade, à propriedade, à igualdade perante a lei. Podem ser compreendidos como a garantia de ir e vir, de optar por um trabalho, de expressar-se livremente, de não ser condenado sem processo legal regular. Direitos estes fundamentados em uma justiça independente, eficiente, barata e acessível a todos, garantindo uma relação civilizada entre os indivíduos (Carvalho, 2007).

Os "direitos políticos" referem-se à participação do cidadão no governo da sociedade. São compreendidos como a capacidade de fazer demonstrações políticas, de organizar partidos, de votar e ser votado (Carvalho, 2007).

Por fim, os "direitos sociais" são aqueles que, conforme Carvalho (2007), garantem a participação na riqueza coletiva. Eles incluem o direito à educação, ao trabalho, ao salário justo, à saúde, à aposentadoria. Os direitos sociais permitem às sociedades politicamente organizadas reduzir os excessos de desigualdade produzidos pelo capitalismo e garantir um mínimo de bem-estar para todos, baseando-se na ideia de justiça social e do estado do bemestar social.

Carvalho (2007) ressalta que a ideia desses direitos foi desenvolvida por T.A. Marshall, com base em uma experiência empírica na Inglaterra. De acordo com Marshall, esse foi um processo gradativo, do qual se partiu da conquista dos direitos civis, para posteriormente conquistar os direitos políticos, e por fim os direitos sociais. De acordo com Carvalho, um dos elementos centrais na conquista desses direitos é a educação popular, considerada um direito social. 
Para Carvalho (1996), o elenco de temas relevantes para a formação da cidadania política pode ser expandido para além do exercício de direitos, conforme apresentado por Marshall. Se a cidadania é concebida como a maneira pela qual as pessoas se relacionam com o Estado, não há por que excluir de seu estudo o cumprimento de deveres cívicos como o serviço militar no Exército, na Armada e na Guarda Nacional.

Outro ponto a ser debatido refere-se ao processo histórico de formação da cidadania. No Ocidente, esse processo seguiu basicamente duas vertentes: um direcionamento de "baixo para cima", por iniciativa dos cidadãos, e outro de "cima para baixo", por iniciativa do Estado e de grupos dominantes (Turner, 1990). Carvalho (2001:1) menciona como exemplos típicos da cidadania de "baixo para cima" "as experiências históricas dos países anglo-saxões, marcadas pela luta para arrancar ao Estado absolutista os direitos civis e políticos". Como marcos desse percurso, Carvalho destaca a Guerra Civil inglesa no século XVII, a Guerra de Independência dos Estados Unidos e a Revolução Francesa no século XVIII. Carvalho (2001) explica que esse tipo de cidadania é caracterizado pela postura ativa dos cidadãos.

Na cidadania construída de "cima para baixo", Carvalho (2001) menciona como exemplo o caso da Alemanha a partir do século XIX. Na Alemanha, notou-se que aos poucos o Estado foi concedendo um conjunto de direitos aos cidadãos. Assim, ser cidadão na Alemanha era praticamente sinônimo de ser leal ao Estado. Nesse caso da cidadania de "cima para baixo", pode-se dizer que ela ocorre de forma passiva no sentido político, mas com um conteúdo ativo de identificação social.

Putnam (2007) realiza outra discussão sobre a construção da cidadania. Em sua obra, Putnam faz um paralelo entre o Norte e o Sul da Itália, estendendo-o para a relação Norte-Sul mundial, em que os países desenvolvidos, em sua maioria, situam-se na parte Norte do globo terrestre, ficando os países menos desenvolvidos na parte Sul. Nesse sentido, certas regiões da Itália, como constatado por Putnam (2007), são favorecidas por padrões e sistemas dinâmicos de engajamento cívico; por outro lado, outras regiões parecem se estruturar em colunas verticalizadas, com uma vida social caracterizada pela fragmentação e pelo isolamento, prevalecendo um sentimento geral de desconfiança. Para Putnam, essas diferenças, na esfera da vida cívica, são fundamentais para explicar o êxito das instituições.

Segundo Putnam (2007), a sociedade dotada de redes de confiança e solidariedade horizontais contribui para a formação de instituições mais sólidas. Como pode ser observado em sua obra, nas comunidades do Norte, o conceito de capital social está introjetado na mente das pessoas, ou seja, nessas comunidades existem padrões de confiança, solidariedade e engajamento cívico; as ações são coordenadas entre indivíduos através de regras de cooperação, fazendo aumentar o desempenho das instituições e a eficiência da sociedade. Já nas regiões do Sul existe grande concorrência entre organizações e entre pessoas. Há a presença de fortes conglomerados empresariais, pautados nos interesses capitalistas, em que se valoriza a concorrência. Essa região é influenciada por grupos poderosos do capital e, portanto, praticamente destituída de um ambiente comunal. Além de as pessoas acharem que vale mais a pena ser "amigo do rei", ou seja, ter um político influente como protetor e tentar conseguir privilégios especiais. 
Todos esses aspectos apresentados nesta seção demonstram os elementos centrais para a constituição de uma cidadania efetiva. Seguindo o propósito deste artigo, na próxima seção apresentaremos uma breve história da formação do Estado brasileiro.

\section{A formação do Estado brasileiro}

O Brasil, na era colonial, caracterizava-se por uma unidade política centrada na imagem de um rei e seus conselheiros. A legislação da colônia era composta por determinações de cunho particular, ou seja, não existiam normas gerais a serem seguidas, hierarquias e definições de competências. A esfera privada confundia-se com a pública, ou, segundo Hollanda (1995), ocorria a invasão do Estado pela família, de modo que os sentimentos relativos a esta, particularista e antipolítica, predominavam em toda a vida social.

Prado Jr. (1994), apud Paes de Paula (2005), também se referindo à época colonial, corrobora a visão de Hollanda (1995), afirmando que existia uma confusão de atribuições e poderes nos órgãos da administração geral e civil. Os postos administrativos caracterizavamse pela não profissionalização, concentrando-se sob o domínio dos nobres ou da burguesia enriquecida. Diante desses fatos, é possível inferir que os cargos públicos administrativos centravam-se muitas vezes nas mãos de indivíduos isentos de competência para ocupá-los.

Nesse mesmo sentido, Paes de Paula (2005) afirma que não havia distinção entre a esfera econômica e a política, acarretando, assim, a apropriação do patrimônio estatal por parte dos representantes do Estado. No período colonial, a administração pública ficou fortemente caracterizada por seu caráter patrimonialista, tornando a organização governamental "muito mais um bem a ser explorado, que uma estrutura funcional a serviço do interesse público" (Paes de Paula, 2005:106). Essa situação perdurou não apenas na época colonial, mas também durante o Império e a República Velha (1889-1930).

As primeiras tentativas de se burocratizar a administração pública ocorreram durante o governo de Getúlio Vargas (1930-45), com a implementação da Reforma Burocrática, visando profissionalizar o funcionalismo público. A criação do Departamento de Administração do Serviço Público (Dasp) foi um marco dessa reforma. A reforma implementada pelo governo Vargas propiciou uma significativa melhora no aparelho estatal, promovendo maior eficiência às atividades do Estado (Paes de Paula, 2005).

No entanto, concomitantemente aos aspectos positivos que puderam ser evidenciados, alguns pontos negativos também foram constatados. Começam a emergir algumas disfunções burocráticas, destacando-se, entre elas, o excesso de autoritarismo, a consolidação de uma cúpula tecnocrática, a ineficiência, a ineficácia, os atrasos, confusões e privilégios (Vasconcelos, 2002).

Com o aumento das disfunções da organização burocrática no decorrer do tempo, alguns países, como os EUA e o Reino Unido, foram impulsionados a buscar novas alternativas para a administração pública. Nesse sentido, surge a Nova Administração Pública (NAP), que buscou suplantar a organização burocrática, trazendo para o âmbito da administração pública 
práticas características da administração privada (Motta, 2007). Esse movimento foi chamado gerencialismo ou administração pública gerencial. Dois grandes exemplos da ascensão desse movimento são o governo de Margareth Thatcher (1979-87), na Inglaterra, e o de Ronald Reagan (1980-88), nos Estados Unidos — ambos de orientação neoliberal.

Thatcher buscou mudar o funcionamento do serviço público inglês e, para tanto, tomou medidas relacionadas à diminuição do número de funcionários e consequente redução do custo, introduziu maior controle das melhorias e executou avaliação de desempenho dos funcionários. Privatizou empresas estatais, criando organismos que regulassem seu funcionamento, e terceirizou serviços públicos, descentralizando as atividades do Estado. Por outro lado, Ronald Reagan deu continuidade à ruptura com o modelo econômico keynesiano, implementando políticas monetaristas anti-inflacionárias e iniciou a desregulamentação da economia. Reagan também promoveu descentralização do Estado realizando privatizações e terceirizações (Paes de Paula, 2005).

Em contrapartida aos ideais neoliberais, emerge na década de 1990 um modelo contrabalanceando os ideais do neoliberalismo e das sociais-democracias, a Terceira Via, cujos princípios são: (1) igualdade, (2) liberdade como autonomia, (3) não há direitos sem responsabilidades, e (4) não há autoridade sem democracia (Giddens, 1999). Enquanto a social-democracia considerava importante a segurança econômica, e o neoliberalismo buscava competitividade e geração de riqueza, a Terceira Via ocupa-se em aliar o dinamismo do mercado com a questão do interesse público. Ainda para Giddens, enquanto os neoliberais defendem um Estado mínimo e os social-democratas desejam expandir o poder do Estado, a política da Terceira Via se propõe a reconstruí-lo.

Embasada nos princípios do gerencialismo, instituídos por Reagan e Thatcher, em 1995 é realizada uma nova reforma do Estado brasileiro, implementada pelo então ministro Bresser-Pereira, no governo do presidente Fernando Henrique Cardoso, introduzindo no país a administração pública gerencial. O Estado passa a ser orientado predominantemente pelos valores de eficiência e qualidade na prestação de serviços públicos e pelo desenvolvimento de uma cultura gerencial nas organizações (Brasil, 1995). Essa reforma tinha como alguns de seus principais pontos: a descentralização política, com a transferência de recursos e atribuições para estados e municípios; a descentralização administrativa, delegando-se autoridade aos administradores públicos; a diminuição dos níveis hierárquicos da administração pública; o controle por resultados; e a administração voltada para os interesses dos cidadãos (BresserPereira, 1996).

A administração pública gerencial teve por objetivo substituir o típico administrador público por gerentes, ou seja, pressupunha uma mudança nos aspetos culturais do Estado, dado que os valores gerenciais deveriam se sobrepor aos burocráticos (Junquilho, 2004). O Estado passaria a incorporar ferramentas próprias do setor privado, administrando os recursos públicos de maneira eficiente para os "cidadãos-clientes".

Ao longo dessa trajetória histórica da administração pública brasileira, cabe ressaltar um marco importante no que se refere à maior participação da sociedade civil. Foi a partir da Constituição Federal de 1988 que foram firmadas as condições para uma democracia par- 
ticipativa. Nesse momento, foi concedido um destaque às organizações não governamentais (ONGs), que passaram a se tornar um meio de diálogo entre a sociedade civil e o Estado (Sucupira et al., 2007). Vale destacar, também, que foi a partir da Constituição de 1988 que os conselhos ganharam maior vigor na gestão pública (Oliveira, 2009). Os conselhos gestores podem ser considerados mecanismos que concretizam os princípios constitucionais de democratização e controle social, ou seja, possibilitam uma administração mais descentralizada e participativa (Moroni e Ciconello, 2005).

A reforma do estado, em 1995, também foi um importante marco, dado que, por meio da descentralização do poder público, novos agentes ganharam espaço nas ações governamentais. Assim, foi reforçada a maior participação das instituições privadas e das organizações não governamentais.

Atualmente, pode-se dizer que os espaços de participação social ganharam maior adesão com o governo de Luiz Inácio Lula da Silva. Entretanto, nota-se que a ausência de uma cultura cívica tem acarretado participação pouco efetiva dos cidadãos na esfera pública. Isso reforça ainda mais a soberania do Estado sobre o povo, levando a um tipo de prática denominada de "estadania". A próxima seção tem por objetivo delinear como os aspectos históricos da política e da gestão pública brasileira propiciaram o fortalecimento de uma "estadania" no Brasil.

\section{Cidadania ou "estadania" no Brasil?}

Para Garcia (2009), o Brasil é um país que apresenta inúmeras peculiaridades, sejam elas históricas, climáticas, geográficas, culturais e étnicas. Entre as inúmeras singularidades que caracterizam essa nação, destaca-se seu aspecto político, ou melhor, a relação construída entre governantes e governados.

De acordo com Garcia, o Brasil não é uma nação de direitos conquistados, mas sim de direitos concedidos. Assim, nota-se que desde o Brasil colônia até os dias atuais a relação entre povo e detentores do poder se caracteriza pela constante subordinação e pelo excesso de autoritarismo.

Norte (2009) explica que a ordem escravocrata e a forte presença do patrimonialismo na elite imperial brasileira não permitiram que o Brasil se desenvolvesse nos moldes do liberalismo, como os Estados Unidos e alguns países da Europa.

Nota-se, segundo Fronzaglia (2007), que o Estado brasileiro é caracterizado por políticas paternalistas e populistas, assimiladas como formas de concessões e benefícios oferecidos pelo governante a seus cidadãos. Fronzaglia acrescenta que essa relação singular entre governantes e governados aproxima-se muito mais de uma relação própria da esfera privada. Essa relação, caracterizada pelo patrimonialismo e pelas ações paternalistas, ocorre na primeira república e adquire novas configurações com o governo populista. Nesse sentido, Fronzaglia (2007) acredita que o desenvolvimento de um Estado democrático foi tolhido pela perpetuação dessas práticas na política brasileira. 
Para Carvalho (2007), a trajetória histórica brasileira revela que a democracia e a cidadania tiveram uma formação distinta da encontrada em outras partes do globo. Carvalho explica que essa formação não seguiu a lógica descrita por Marshall. No Brasil, em primeiro lugar vieram os direitos sociais, em seguida os direitos políticos, e por fim os direitos civis. Nesse caso, pode-se afirmar que a pirâmide dos direitos estabelecidos por Marshall encontrase invertida na realidade brasileira. Vale destacar, também, que a implementação de cada um desses direitos não ocorreu de forma ideal e satisfatória. Carvalho (2007) comenta que parte desses direitos continua inacessível a uma grande parcela de brasileiros.

Fronzaglia (2007) acrescenta que os fatos que marcaram a trajetória histórica brasileira funcionaram como obstáculos para a formação de uma cultura cívica consolidada.

Carvalho (2001) ressalta que o Brasil pode ser enquadrado entre aqueles países que desenvolveram sua cidadania de "cima para baixo". Carvalho comenta que a independência se fez sem revolução social e política. O mesmo se deu com a proclamação da República e com o movimento de 1930, embora este último tenha recebido o nome de revolução. Carvalho completa comentando que até nos dias atuais a incorporação da sociedade civil é precária, embora seja garantida em lei.

Apesar de a reforma do Estado, em 1995, ter permitido a maior descentralização do poder público, possibilitando a atuação da sociedade, das instituições privadas e da sociedade civil, nota-se ainda que a interação Estado-sociedade é fortemente marcada pelo caráter inativo da segunda.

Como mencionado na seção anterior, os conselhos gestores foram instrumentos fundamentais, criados pelo Estado, para efetivar a participação social nas decisões de cunho estatal. Entretanto, nota-se que esses espaços pouco têm sido aproveitados pela sociedade civil. Esse aspecto pode ser justificado pela própria condução da administração pública brasileira, que se caracterizou desde o período colonial por uma relação de autoritarismo. Essa cultura orientada mais para o Estado do que para a representação é chamada de estadania, em contraste com a cidadania (Carvalho, 2007).

Assim, no Brasil nota-se, de acordo com Moura e Silva (2008), a predominância de perspectivas que conferem uma primazia do Estado, como ator protagonista na estruturação da vida social, prevalecendo assim uma concepção "estatista”, a qual confere ao Estado a capacidade de iniciativa e de condução da dinâmica sociopolítica e/ou da modernização do país, cabendo aos atores não estatais um papel de coadjuvantes destituídos de agência.

Para Carvalho (2001), no Brasil não predomina uma tradição de vida civil ativa, o que fortalece a premissa de que o Estado sempre assumiu uma postura central na relação entre poder público e sociedade. Adicionalmente, verifica-se que o poder público não é garantidor dos direitos de todos, mas de grupos econômicos e de cidadãos que com ele tecem uma rede clientelista de distribuição particularista de bens públicos.

Essa cultura "estatista" favorece, também, uma visão corporativa dos interesses coletivos. Segundo Carvalho (2007), a ausência de ampla organização autônoma da sociedade faz com que os interesses corporativos prevaleçam. Assim, a representação política não funciona 
com a finalidade de resolver os problemas que assolam a maioria da população, mas sim para atender os interesses pessoais.

No Brasil, diversos fatos da história da administração pública propiciaram o fortalecimento de uma "estadania". A crescente desigualdade social do país estimula a consolidação de uma cultura muito pouco favorável à ação coletiva e aos valores igualitários, fundamentais à democracia. Ribeiro (2007) destaca que a democracia exige a participação de pessoas dotadas de autonomia moral. Essa autonomia moral demanda um grau razoável de independência e segurança econômica. Assim, Ribeiro defende a ideia de que no Brasil predomina uma "democracia representativa excludente", em que poucos desfrutariam da real condição de cidadania.

Outro entrave para a consolidação de uma efetiva cidadania é a presença da corrupção na política brasileira. De acordo com Khan (2001), estudos empíricos comprovaram que a corrupção apresenta um movimento inverso ao crescimento e à produtividade, dado que ela inclui o abuso de autoridade, suborno, favoritismo, extorsão, fraude, clientelismo e ilegalidade nos processos. Tendo essas características que marcam a corrupção, conclui-se que esta e o sistema democrático não deveriam coexistir, dado que a primeira implica muitos riscos para o segundo. Mesmo assim, nota-se que em grande parte das nações o regime democrático convive com a corrupção. É por essa razão que a democracia não se desenvolve de maneira plena em grande parte dos países.

Diante de todas essas considerações apresentadas, sobre a relação entre governantes e governados, e a supremacia de uma cultura "estatista", chama-se a atenção para a necessidade de revisar o papel do Estado. Como o poder público sempre exerceu uma função de protagonista, não é necessário que a sociedade civil se volte contra o Estado, mas sim contra o Estado clientelista, corporativo e colonizado (Carvalho, 2007). É necessário que a sociedade aproveite de fato esses espaços de participação concedidos pelo poder público, pois esse pode ser o primeiro passo para a construção de uma efetiva cidadania brasileira.

\section{Considerações finais}

Objetivou-se com este artigo teórico apresentar os elementos centrais sobre democracia e cidadania e demonstrar como a formação histórica do Estado brasileiro impulsionou o fortalecimento de uma "estadania" nacional em detrimento da cidadania. Para tanto, este artigo perpassou pelos elementos centrais da democracia e da cidadania, reconstituiu a trajetória histórica da formação do Estado brasileiro, e, em última instância, demonstrou como essa história se constituiu em um entrave para a construção de uma efetiva cidadania, ressaltando, portanto, a prática da "estadania".

Como pôde ser observado, o processo de formação do Estado brasileiro ocorreu com a colonização portuguesa, em que os interesses do rei prevaleciam sobre os interesses do povo. O importante neste comentário é sua magnitude, isto é, desde os tempos de colônia o país não se desenvolveu de forma democrática, muito menos cidadã. 
Hoje, com o passar do tempo, observa-se a preocupação de nossos líderes em implementar a democracia; alguns até dizem que nossa Constituição de 1988 é uma das constituições mais cidadãs do mundo. Isto até é verdade em termos formais, no papel; porém, ao nos depararmos com a realidade, isto não ocorre de fato. No governo de Fernando Henrique Cardoso (FHC), observa-se uma preocupação em relação à modernização da administração pública brasileira, no sentido de tornar o Estado cada vez mais descentralizado, democratizando a gestão por meio da participação de novos agentes - instituições privadas e terceiro setor. Nota-se que no governo de Luiz Inácio Lula da Silva há um seguimento, mesmo que parcial, das ações planejadas pelo governo de FHC. Nesse sentido, preocupado com a maior democratização da gestão estatal, revitaliza-se a atuação dos conselhos gestores, "garantindo", assim, a maior participação dos cidadãos nas decisões de cunho estatal.

Contudo, como foi demonstrado neste artigo, o que prevalece na história do Estado brasileiro são aspectos patrimonialistas, que se desenvolvem como grandes instrumentos para manutenção do poder.

Dessa forma, nota-se que ao longo de todo o processo histórico existiu um distanciamento entre o Estado e o cidadão, mesmo ocorrendo tentativas de aproximar esses dois atores. Esse distanciamento é denominado por Motta (2007) a síndrome do "nós-eles", em que parcelas da população tendem a ver seus dirigentes e representantes políticos como outro tipo de classe. Essa síndrome é um grande entrave no processo de democratização do país, além de interferir diretamente na construção da cidadania. Ademais, existem problemas associados à corrupção e ao favoritismo, em que os interesses de um pequeno grupo prevalecem em relação aos da maioria dos cidadãos.

Apesar de todos esses aspectos mencionados, existe uma possibilidade de avanço em relação ao processo de democratização, bem como da cidadania. Esse avanço pode ser evidenciado pela criação de organizações e associações comunitárias, as quais assumem funções que antes eram de responsabilidade do Estado. Contudo, vale ressaltar que, de acordo com Motta (2007), à medida que elas se fortalecem, passam a ter um poder de influência muito grande perante o Estado e assim são capazes de intervir em benefício próprio. Acredita-se que isso realmente seja um entrave, porém a criação das mesmas representa uma tentativa mínima de democratização. Por outro lado, Kim (2007) acrescenta que quando há uma alteração de um governo coercitivo para um colaborativo, o que representa uma mudança a favor da democracia, há necessidade de as pessoas se adaptarem a esse novo tipo de conduta.

Assim, o que se percebe é que o exercício da democracia não é uma tarefa nada fácil, porém para uma nação evoluir em termos de participação efetiva dos cidadãos é fundamental a entronização dos mesmos no processo. No caso brasileiro, nota-se que há um predomínio de ações que conferem maior poder ao Estado, como responsável pela estruturação e desenvolvimento da vida social. Portanto, prevalece em nossa nação a "estadania", visto a ausência de uma cultura cívica, cabendo aos atores não estatais um papel de coadjuvantes nesse processo.

Nesse contexto, fazem-se necessárias várias mudanças, entre as quais destacamos duas: por um lado, é preciso democratizar cada vez mais o próprio Estado, consolidando as instituições democráticas; por outro, é necessário democratizar a própria democracia, como bem 
apresenta essa ideia Souza Santos (2006). São mudanças que precisam ser construídas a cada dia de nossa história e, especialmente, da gestão pública.

\section{Referências}

BOBBIO, N. O futuro da democracia: uma defesa das regras do jogo. Rio de Janeiro: Paz e Terra, 1986.

BRASIL. Ministério da Administração e Reforma do Estado. Plano diretor da reforma do aparelho do Estado. Brasília, 1995. Disponível em: <www.planalto.gov.br/publi_04/COLECAO/PLANDI. HTM>. Acesso em: 10 dez. 2007.

BRESSER-PEREIRA, L.C. Da administração pública burocrática à gerencial. Revista do Serviço Público, v. 47, n. 1, p. 7-29, 1996.

BURRELL, G.; MORGAN, G. Sociological paradigms and organizational analysis. London: Heinemann, 1979.

CARVALHO, J.M. Cidadania no Brasil: o longo caminho. 9. ed. Rio de Janeiro: Civilização Brasileira, 2007.

CARVALHO, J.M. Cidadania, estadania, apatia. Jornal do Brasil, Rio de Janeiro, p. 8, 24 jun. 2001.

CARVALHO, J.M. Cidadania: tipos e percursos. Estudos históricos, Rio de Janeiro, n. 18, 1996.

DAHL, R. Sobre a democracia. Brasília: UnB, 2001.

FRONZAGLIA, M.L. Estado, cidadania e políticas de bem-estar no Brasil: uma abordagem histórica. Revista Mackenzie, São Paulo, n. 3, B07, 2007.

GARCIA, G.P. Estadania $\times$ cidadania. 2009. Disponível em: <www.pradogarcia.com.br>

GIDDENS, A. A terceira via. Rio de Janeiro: Record, 1999.

HOLLANDA, S.B. de. Raízes do Brasil. São Paulo: Companhia das Letras, 1995.

JUNQUILHO, G.S. Nem "burocrata" nem "novo gerente": o "caboclo" e os desafios do plano diretor de reforma do Estado no Brasil do real. Revista de Administração Pública, Rio de Janeiro, v. 38, n. 1, p. 137-156, jan./fev. 2004.

KHAN, M.M. Problemas de la democracia: reforma administrativa y corrupción. Gestión y Política Pública, México, n. 2, p. 253-273, 2001.

KIM P.S. Desafíos a la capacidad pública en la era de una administración pública em evolución y reforma del gobierno. Gestión y Política Pública, v. 26, 2º sem. 2007.

MARSHALL, T.H. Cidadania, classe social e status. Zahar: Rio de Janeiro, 1967.

MORONI, J.A.; CICONELLO, A. Participação social no governo Lula. Avançamos? In: A Abong nas conferências 2005 - Criança e adolescente - Assistência social. Brasília: Abong, nov. 2005. 
MOTTA, P.R. A modernização da administração pública brasileira nos últimos 40 anos. Revista do Serviço Público, ed. Especial, Rio de Janeiro, 2007.

MOURA, J.T.V.; SILVA, M.K. Atores sociais em espaços de ampliação da democracia: as redes sociais em perspectiva. Revista Sociologia Política, Curitiba, v. 16, n. suplementar, p. 43-54, ago. 2008.

NORTE, S.A.Q. Da "estadania" à cidadania. 2009. Disponível em: < http://pascal.iseg.utl.pt/ $\sim$ socius/1/conf_cd/da.pdf $>$.

OLIVEIRA, V.C.S. Sociedade, Estado e administração pública: análise da configuração institucional dos conselhos gestores do município de Lavras/MG. Tese (doutorado) — Universidade Federal de Lavras, Lavras, 2009.

PAES DE PAULA, A.P. Por uma nova gestão pública: limites e potencialidades da experiência contemporânea. Rio de Janeiro: FGV, 2005.

PUTNAM, R.D. Comunidade e democracia: a experiência da Itália moderna. Rio de Janeiro: FGV, 2007.

RIBEIRO, L.C.Q. Desafios da construção da cidadania na metrópole brasileira. Sociedade e Estado, Brasília, v. 22, n. 3, p. 525-544, set./dez. 2007.

SOUZA SANTOS, Boaventura de. Reinventar la democracia: reinventar el Estado. Buenos Aires: Clacso, 2006.

SUCUPIRA, L.A.; CHAVES, A.D.; MONTEIRO, M.G. ONGs e Estado: entre a retórica e a prática. In: ENCONTRO DA ASSOCIAÇÃO NACIONAL DE PÓS-GRADUAÇÃO E PESQUISA EM ADMINISTRAÇÃO, 31., 2007, Rio de Janeiro, 2007. Anais... Versão eletrônica. Rio de Janeiro: Anpad, 2007.

TENÓRIO, F.G. (Org.). Cidadania e desenvolvimento local. Rio de Janeiro: Unijuí, 2007.

TOCQUEVILLE, A. A democracia na América. Belo Horizonte: Itatiaia, 1987.

TORAINE, A. O que é democracia. São Paulo: Edusp, 1996.

TURNER, B.S. Outline of a theory of citizenship. Sociology, v. 24, n. 2, p. 189-217, May 1990.

VASCONCELOS, F.C. Racionalidade, autoridade e burocracia: as bases da definição de um tipo organizacional pós-burocrático. In: ENCONTRO NACIONAL DE ESTUDOS ORGANIZACIONAIS, Recife, 2002. Anais... Versão eletrônica. Recife: Eneo, 2002.

Daniela Meirelles Andrade é professora do Departamento de Administração e Economia da Universidade Federal de Lavras (Ufla). E-mail: danimeirellesandrade@hotmail.com.

Carolina Lescura de Carvalho Castro é professora assistente do Departamento de Turismo da Universidade Federal Fluminense (UFF). E-mail: carolescura@gmail.com.

José Roberto Pereira é professor associado da Ufla. E-mail: jrobpereira@yahoo.com.br. 